\title{
Structural Grades of Timber by Bending and Compression Tests
}

\author{
Jorge Branco ${ }^{1, \mathrm{a}}$, Humberto Varum ${ }^{2, \mathrm{~b}}$ and Paulo $\mathrm{Cruz}^{1, \mathrm{c}}$ \\ ${ }^{1}$ DECivil - Engineering School, Campus de Azurém, 4800-058 Guimarães, Portugal \\ 2 DECivil, Campus Universitário de Santiago, 3810-193 Aveiro, Portugal \\ ajbranco@civil.uminho.pt, ${ }^{b}$ hvarum@civil.ua.pt, ${ }^{c}$ pcruz@civil.uminho.pt
}

Keywords: Timber, structural grades, mechanical tests, bending and compression

\begin{abstract}
This paper presents the results obtained in a series of tests on Pinus Pinaster Ait. timber specimens, using the prEN408:2000, to estimate the local and global Young's modulus and strength both in bending and compression parallel to the grain. The results obtained are compared with the values presented in the Portuguese Nationally Determined Parameters of Eurocode 5, for the quality classes assign by Portuguese Standard NP4305:1994 by visual grading.
\end{abstract}

\section{Introduction}

The results achieved in any assessment of mechanical properties are function of the testing method adopted. Timber mechanical properties depend of various factors, as for instance: load duration, moisture content, span, depth of the section, etc. Therefore, to accomplish the comparison between the results obtained in different laboratories, a standardization of the test procedure is required. Moreover, with the adoption of limit state design and with the development of both visual and machine stress grading, attention will be increasingly focused on the determination and monitoring of the strength properties and variability of structural grades of timber.

The prEN408:2000 European Standard specifies laboratory methods for the determination of some physical and mechanical properties in structural sizes. This standard presents test methods for determining the modulus of elasticity, the bending strength and the compression strength in a parallel direction to the grain orientation in structural timber. In addition, the determination of dimensions, moisture content and density are specified. In follow the bending and compression tests procedure adopted by prEN408:2000 are described.

Bending Test. This test use a piece simply supported with a span of 18 times the depth with the loads points placed on the third of the span, as it is shown in Fig. 1. Small steel plates of length not greater than one-half of the depth of the test piece may be inserted between the piece and the loading heads supports to minimize local indentation.

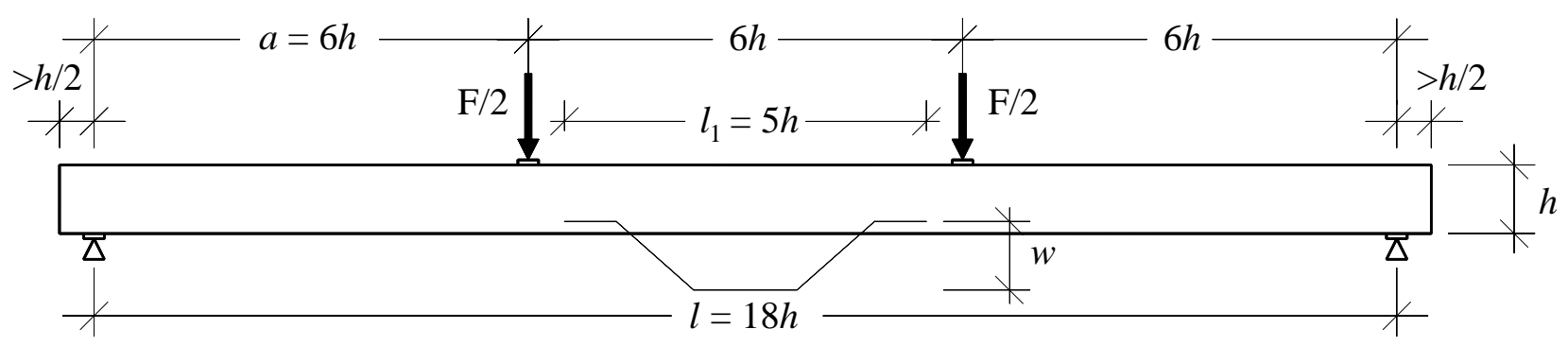

Fig. 1 - Test arrangement of the bending test

The evaluation of the modulus of elasticity in bending is based on the deformations measured at the centre of a central gauge length of 5 times the depth of the section. This deformation shall be taken as the average of measurements on both faces at the neural axis. 
The local modulus of elasticity in bending $\left(E_{m, l}\right)$ is obtained from the follow equation:

$$
E_{m, l}=\frac{a l_{1}^{2} \Delta F}{16 I \Delta w} .
$$

where $\Delta F$ is an increment of load on the straight-line portion of the load deformation curve ( $\mathrm{N}$ ), $\Delta w$ is the increment of deformation corresponding $(\mathrm{mm}), a$ is the distance between a loading position and the nearest support (mm), $l_{1}$ is the gauge length $(\mathrm{mm})$ and $I$ is the second moment of area $\left(\mathrm{mm}^{4}\right)$.

Using the deformation value measured at the centre of the span and at the centre of the compression or tension edge we can also calculate the value of the global modulus of elasticity in bending. Thus, the global modulus of elasticity in bending $\left(E_{m, g}\right)$ is obtained from the follow equation:

$$
E_{m, g}=\frac{l^{3} \Delta F}{b h^{3} \Delta w}\left[\left(\frac{3 a}{4 l}\right)-\left(\frac{a}{l}\right)^{3}\right] .
$$

where $b$ and $h$ are the width and depth of the cross section (mm), respectively, $l$ is the span (mm).

The bending strength is obtained with the continuation of the test just to failure, applying the load with a constant loading-head movement so adjust that maximum load is reached within (300 \pm 120$)$ s. Therefore, the bending strength $\left(f_{m}\right)$ is given by:

$$
f_{m}=\frac{a F_{\max }}{2 W} \text {. }
$$

where $F_{\max }$ is the maximum load $(\mathrm{N})$ and $W$ is the section modulus $\left(\mathrm{mm}^{3}\right)$.

Compression Test. In this test, the test piece shall be of full cross section, and shall have a length of 6 times the smaller cross-sectional dimension. The end surfaces shall be accurately prepared to ensure that they are plane and parallel to one another and perpendicular to the axis of the piece. The load shall be applied concentrically using spherical seated loading-heads permitting the application of a compressive load without inducing bending. Deformation shall be measured over a central gauge length of 4 times the smaller cross-sectional dimension of the piece, using two mechanical strain gauges positioned in such way that the eventual effects of distortion shall be minimized. The modulus of elasticity in compression parallel to the grain $\left(E_{c, 0}\right)$ is given as the result of:

$$
E_{c, 0}=\frac{l_{1} \Delta F}{A \Delta w} .
$$

where $A$ is the cross-sectional area $\left(\mathrm{mm}^{2}\right)$.

The compression strength is obtained with the increment of the load, applied at a constant loading-head movement so adjusted that maximum load $\left(F_{\max }\right)$ is reached within $(300 \pm 120)$ s. The compression strength $\left(f_{c, 0}\right)$ is taken as the result of the follow equation:

$$
f_{c, 0}=\frac{F_{\max }}{A} .
$$

The mode of fracture and growth characteristics at the fracture section of each test piece shall be reported.

\section{Experimental Activity}

The experimental program is based on Pinus pinaster Ait. specimens classified as belonging to quality class EE in result of a visual strength grading conducted following the National Standard NP 4305:1995 [2]. In both tests kinds conducted, the failure time was register and the moisture content of each specimen was measure with an electronic thermo-hygrometer for wood. The tests 
were carried out at the Structural Laboratory of the Civil Engineering Department of the Minho University.

Bending Tests. Four beams with a cross section of 80x105 mm and $1.95 \mathrm{~m}$ length were evaluated by four-points bending tests using a test arrangement following prEN 408:2000 (see Fig. 1). A displacement control procedure $(0.14 \mathrm{~mm} / \mathrm{s})$ with an actuator having a capacity of $100 \mathrm{kN}$ has been used. In each test, apart the registration of the deformations measured at the centre of a central gauge length of 5 times the depth of the section, the deformations at the centre of the span at the centre of the tension side edge were measured. With the deformations values corresponding to the elastic deformation the calculation of the local and global values of the modulus of elasticity in bending were possible. Incrementing the load, it was also possible to obtain the bending strength as it was previously explained (Eq. 3). The bending tests results founded are presented in Table 1.

Table 1 - Bending tests results

\begin{tabular}{ccccccc}
\hline Beam & Moisture (\%) & $F_{\max }(\mathrm{kN})$ & Time $(\mathrm{s})$ & $E_{m, l}\left(\mathrm{~N} / \mathrm{mm}^{2}\right)$ & $E_{m, g}\left(\mathrm{~N} / \mathrm{mm}^{2}\right)$ & $f_{m}\left(\mathrm{~N} / \mathrm{mm}^{2}\right)$ \\
\hline B1 & 24.3 & 24.32 & 415 & 10249 & 9902 & 54.71 \\
B2 & 22.3 & 11.99 & 207 & 8894 & 8666 & 26.98 \\
B3 & 23.8 & 19.60 & 374 & 12730 & 11207 & 44.10 \\
B4 & 29.8 & 19.76 & 380 & 9835 & 9658 & 44.45 \\
\hline & & & Mean & 10427 & 9858 & 42.56 \\
& & & CoV & 0.16 & 0.11 & 0.27 \\
\cline { 3 - 6 } & & & & & &
\end{tabular}

Like it was expected, the local value for the modulus of elasticity $\left(E_{m, l}\right)$ was always higher than the global value $\left(E_{m, g}\right)$ as no shear deformation is taken into account in first value contrarily to the second. However the pleasants coefficients of variance (CoV) presented by both modulus of elasticity $\left(E_{m, l}=0.16\right.$ and $\left.E_{m, g}=0.11\right)$, beam B4 did not reached the bending strength level presented by the others beams. As Fig. 2 show, the maximum load reached by B4 stay quite far from the others results, with direct consequences in the bending strength $\mathrm{CoV}(0.27)$.

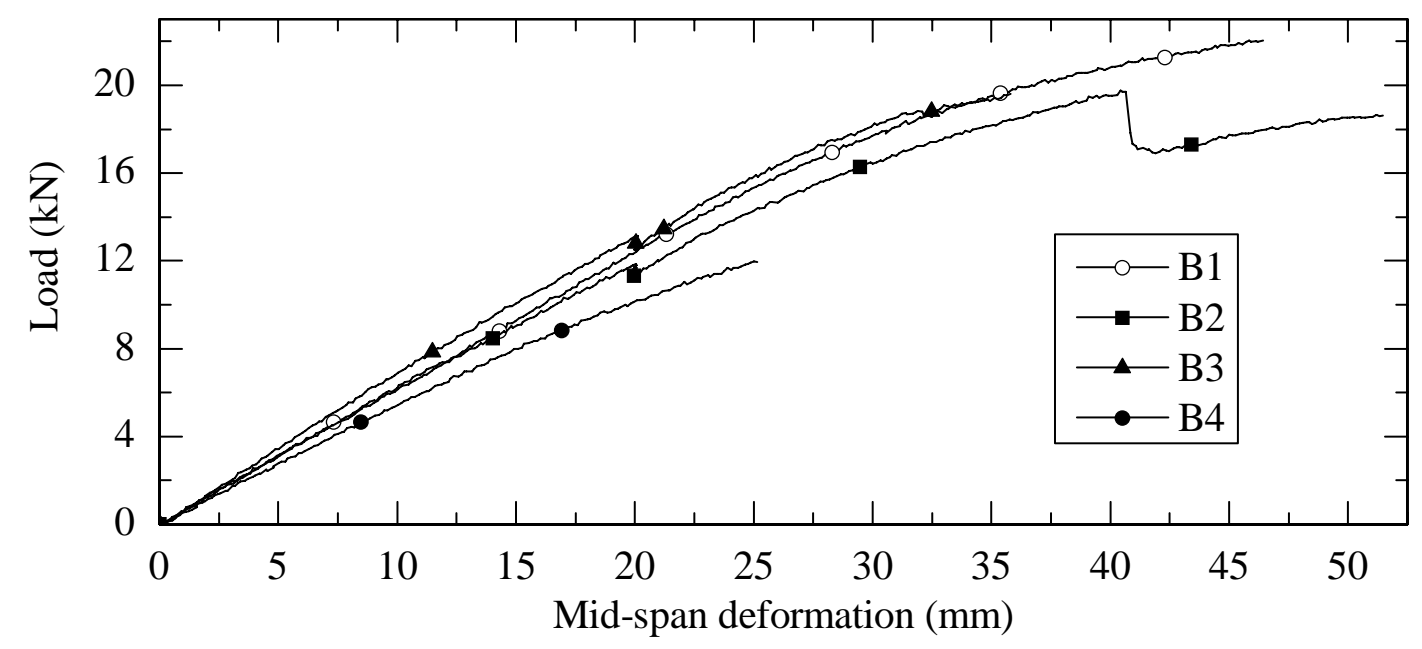

Fig. 2 - Mid-span deformation vs load curves obtained in the bending tests

Compression Tests. Four specimens of $80 \times 105 \times 480 \mathrm{~mm}^{3}$ were used in the compression tests conducted in accordance with the recommendations presented by prEN 408:2000. The tests were performed under displacement control with a velocity of $0.01 \mathrm{~mm} / \mathrm{s}$ using a load cell of $500 \mathrm{kN}$. Two mechanical strain gauges (one in each the two bigger cross-sectional dimensions) were used to measure the deformations and one additional LVDT (Linear Variable Displacement Transducer) was placed in the loading head of the test machine, measuring thereby the grain displacement 
presented by the specimens. After the moisture content measurement, the specimens were tested

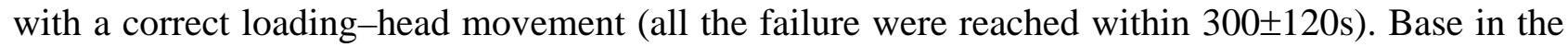
mean values of the deformation measured by the two mechanical strain gauges (in the range of elastic deformation) it was possible to calculated the modulus elasticity $\left(E_{c, 0}\right)$ and with the maximum load value the calculation of the compression strength $\left(f_{c, 0}\right)$. Table 2 shows the compression tests results carried out.

Table 2 - Compression tests results

\begin{tabular}{cccccc}
\hline Specimen & Moisture (\%) & Time $(\mathrm{s})$ & $F_{\max }(\mathrm{kN})$ & $E_{c, 0}\left(\mathrm{~N} / \mathrm{mm}^{2}\right)$ & $f_{c, 0}\left(\mathrm{~N} / \mathrm{mm}^{2}\right)$ \\
\hline S1 & 16.9 & 236 & 160.36 & 4375 & 19.09 \\
S2 & 15.5 & 295 & 177.03 & 6310 & 21.08 \\
S3 & 18.9 & 366 & 224.65 & 9054 & 26.74 \\
S4 & 17.5 & 410 & 295.85 & 7132 & 35.22 \\
\hline & & Mean & 214.47 & 6718 & 25.53 \\
& & CoV & 0.28 & 0.29 & 0.28 \\
\cline { 2 - 5 } & & & & &
\end{tabular}

It is clearly show by the results achieved that the compression behaviour of timber is quite heterogeneous. The coefficient of variance presented by the modulus of elasticity and strength round 0.3. This conclusion is confirmed by the observation of the experimental grain displacement-load curves presented in Fig. 3.

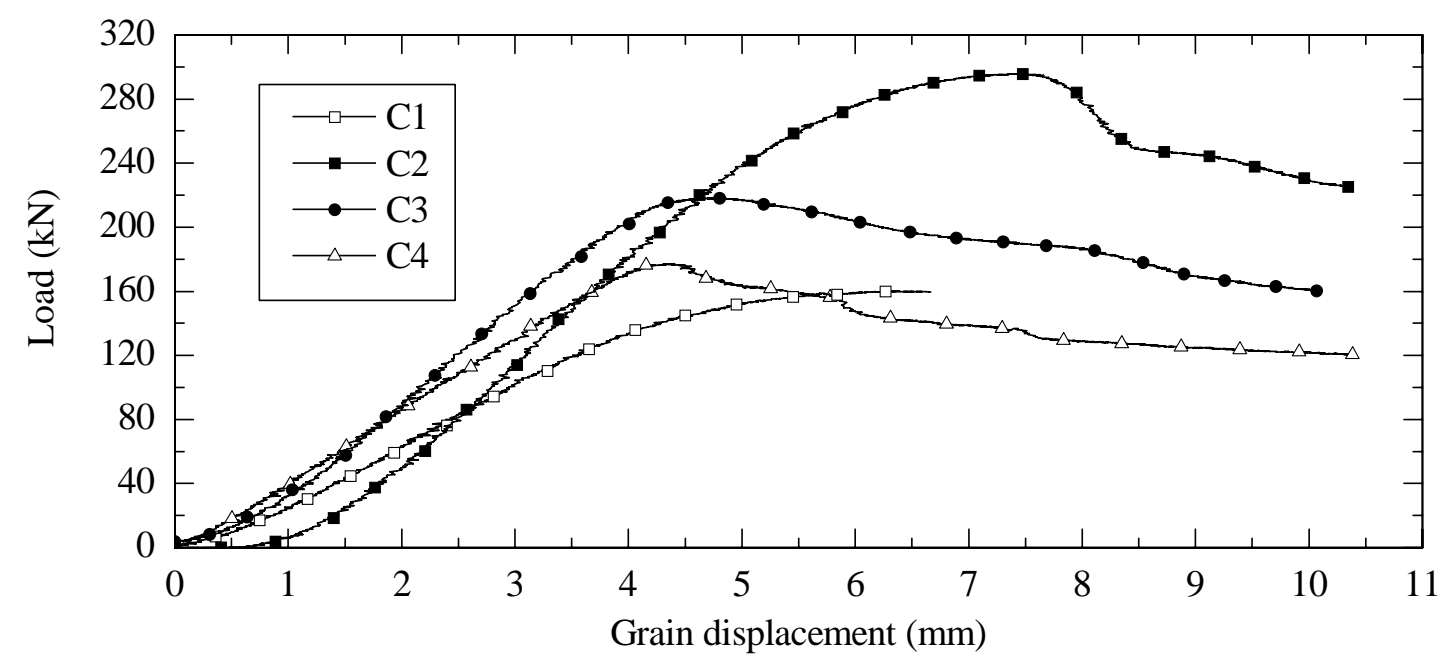

Fig. 3 - Grain displacement - load curves obtained in the compression tests

The Fig. 3 confirm the plastic behaviour recognize to wood under compression parallel to grain and point out a good softening in the grain displacement-load curves.

\section{Discussion of the Results}

On the basis of the experimental results, it can be stated the pleasant homogeneity presented by the bending behaviour, especially in terms of elastic modulus. The local modulus of elasticity in bending $\left(E_{m, l}\right)$ presented a CoV equal to 0.11 while the global modulus of elasticity $\left(E_{m, g}\right)$ achieved showed a $\mathrm{CoV}$ of 0.16 . In terms of the compression parallel to grain tests results, although the plastic behaviour obtained and the ductile failures achieved, a significant variability was pointed out. Coefficients of variations near of 0.3 were obtained for the elastic modulus and strength.

When comparing the experimental results with the values reported in the Portuguese Nationally Determined Parameters of Eurocode 5 (DNA-EC5) [3], for the quality class assign in the visual grading performed following NP4305:1995 [2] (Table 3), different conclusions are reached: (1) the bending strength achieved is $21.6 \%$ higher than the characteristic value assumed by the National Standard; (2) the mean value obtained for the modulus of elasticity $\left(E_{m, l}\right)$ is $34.2 \%$ smaller that the 
one suggest by DNA-EC5; and (3) good agreement between the compression strength value adopted in the DNA-EC5 and the experimental results. If the experimental result was $25.53 \mathrm{MPa}$, DNA-EC5 suggests $24.7 \mathrm{MPa}$ as the characteristics value for the compression strength parallel to the grain. In this standard any value of modulus of elasticity in compression parallel to the grain is presented.

Table 3 - Mechanical properties of Pinus Pinaster Ait. Class EE [3]

\begin{tabular}{cccc}
\hline Class & $E_{m}\left(\mathrm{~N} / \mathrm{mm}^{2}\right)$ & $f_{m}\left(\mathrm{~N} / \mathrm{mm}^{2}\right)$ & $f_{c, 0}\left(\mathrm{~N} / \mathrm{mm}^{2}\right)$ \\
\hline $\mathrm{EE}$ & 14000 & 35 & 24.7 \\
\hline
\end{tabular}

It is important to remember that the values exposed in the DNA-EC5 were obtained on specimens free from faults, with non-structural dimensions and with a moisture content of $12 \%$. It is recognize that the mechanical characterization of wood by means of tests on specimens in small dimension can be inadequate to have reliable and complete information on the structural behaviour of timber elements and structures. For instance, the failure modes obtained in the bending tests conducted are quite different from typical bending failure characteristic of small pieces free from faults, Fig. 4 (a). The existence of knots does not allow the development of the plastic behaviour in the compression side of the cross section (see Fig. 2). Failure append in the tension side and progress rapidly under influence of shear forces without any plastification of the compression side, while the formation of a plastic hinge in the compression side is always obtained in specimens free from faults. In compression, also the existence of faults can determine the failure mode. If in this kind of test the failure mode is more and less constant, is development is always stipulate by the presence of knots, reaction wood, etc., Fig. 4 (b).

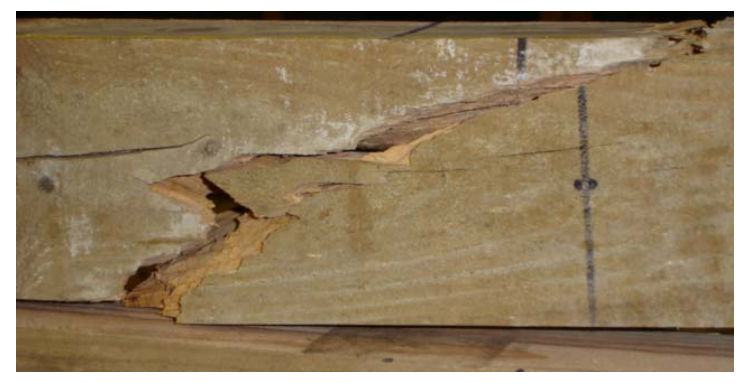

(a) Bending test $-\mathrm{B} 2$

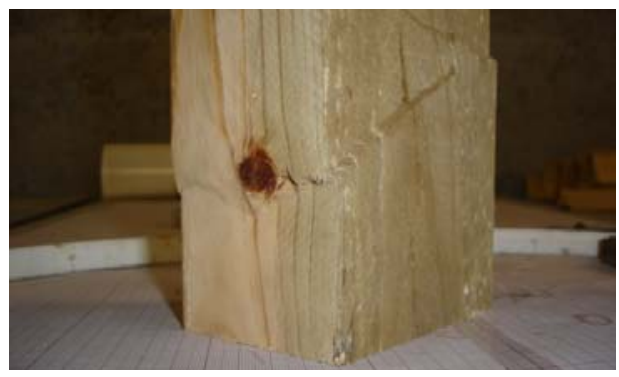

(b) Compression test - S3

Fig. 4 - Failure modes obtained in the experimental work

\section{Conclusions}

With a natural material like wood, so depending of the existence of faults, the mechanical evaluation can not use small specimens free from faults, especially when their presence have the importance showed in this work. Attention has to be moved towards the experimental investigation of the mechanical evaluation of wood elements having structural dimensions and presenting the natural faults recognize to this material.

\section{References}

[1] prEN 408:2000: Timber structures - Structural timber and glued laminated timber Determination of some physical and mechanical properties, CEN, 2000.

[2] NP 4305:1995: Structural maritime pine swan timber - Visual grading, CT 14 LNEC, 1995.

[3] NP ENV 1995-1-1:1998: Eurocódigo 5 - Projecto de estruturas de Madeira. Parte 1-1: Regras gerais e regras para edifícios. CT 115 LNEC, 1998. 